\title{
Determination of SOX9 Gene Expression In Brain Tumours Among East Coast Malaysia Population
}

\author{
Md Dzali NB ${ }^{a}$, Wan Taib WR ${ }^{a}$, Zahary $M N^{a}$, Abu Bakar $N H^{b}$, Abd Latif AZ ${ }^{b}$, Ahmad F , Jaafar $H^{d}$ \\ ${ }^{a}$ Faculty of Health Sciences, Universiti Sultan Zainal Abidin, Gong Badak Campus, Kuala Nerus, Terengganu, \\ Malaysia. \\ ${ }^{\mathrm{b}}$ Faculty of Medicine, Universiti Sultan Zainal Abidin, Medical Campus, 20400 Kuala Terengganu, \\ Terengganu, Malaysia. \\ ${ }^{\mathrm{C}}$ Neuroscience Unit, School of Medical Sciences, Health Campus, Universiti Sains Malaysia,16150 Kubang \\ Kerian, Kelantan, Malaysia \\ ${ }^{\mathrm{d}}$ Department of Pathology, School of Medical Sciences, Health Campus, Universiti Sains Malaysia,16150 \\ Kubang Kerian, Kelantan, Malaysia
}

\section{ABSTRACT}

Introduction: SOX9, a members of SOX family, plays a significant roles in developmental processes during embryogenesis, including brain tissue. Few studies have shown that SOX9 has been involved in tumourigenesis of several types of cancer including brain tumour. However, such studies are still lacking in the Malaysian population. The aim of this study was to determine SOX9 expression level in several types of brain tumours in East Coast Malaysia. Materials and Methods: Five formalin-fixed pariffin-embedded brain tumour samples of Malay descendants were sectioned by using microtome. RNA extraction was performed with slight modification by adding Trizol during tissue lysis. The RNA was converted to CDNA using reverse transcription technique before SOX9 expression was detected using RT q-PCR assay in brain tumours normalized to non-neoplastic brain tissues. Results: Overall results displayed that SOX9 gene in all samples were up-regulated. SOX9 overexpression was found in both high and low grade glioma (anaplastic and pilocytic astrocytoma respectively). This is consistence with both low grade (benign) and atypical meningioma. Secondary brain tumour also showed up-regulation when compared to normal brain tissue. Conclusion: Up-regulation in SOX9 expression in selected brain tumours in Malay patients revealed its significant roles in brain tumourigenesis. Functional studies should be carried out to observe the SOX9 functions and mechanism whether they should reflect their diverse roles in Malaysia population.

KEYWORDS: SOX9, brain tumours, qPCR, glioma, meningioma

\section{INTRODUCTION}

Increasing pattern of brain tumour incidences were reported in Malaysia from 1996 to 2012., ${ }^{1,2}$ Sarawak, a state in East Malaysia, recorded increasing trend of brain tumour and spinal tumour incidence from 2009 to $2012 .^{2}$ Brain tumour is not among the commonest malignancies in Malaysia, but reported to have high incidence and mortality globally and the most promptly fatal type of cancers. ${ }^{3}$ Increasing number

Corresponding Author:

Dr. Wan Rohani Wan Taib,

Faculty of Health Sciences,

Universiti Sultan Zainal Abidin,

Gong Badak Campus, Kuala Nerus,

Terengganu, Malaysia.

Tel : +6016-9712549

Email : wanrohani@unisza.edu.my of cases each year is certainly not a good sign to the healthcare providers and researchers.

The most common adult brain tumour is meningioma with the common variant found to be meningothelial WHO grade I. ${ }^{2,4}$ This is followed by glioma as the second most common adult brain tumour. ${ }^{4}$ In addition, metastatic brain tumour has also shown a rising pattern these days. ${ }^{5,6}$

SOX9 plays a significant role in the developmental processes during embryogenesis including differentiation and lineage commitment which involves various type of tissues including brain. ${ }^{7}$ Many studies have proven that SOX9 and the other members of SOX E (SOX8 and SOX10) contributed to CNS development. ${ }^{8-11}$ SOX9 which is a member of the SOX E family has been shown to play a 
critical role in both embryonic and adulthood CNS, and is a key determinant in the neural stem cells (NSCs) multipotency. ${ }^{12,13}$ There are several molecular and signalling pathways which are related to SOX9 expression. SOX9 acts as mediator for Sonic Hedgehod (SHH) and Notch Pathways to enhance NSC activities. In addition, SOX9 induction by $\mathrm{SHH}$ signalling causing neuroepithelial cells to gain ability to form a neurosphere. ${ }^{12}$

Cancer progression can be triggered when the regulation of differentiation routes and stem cell maintenance in tissues are disturbed. The function of SOX9 in maintaining progenitor cells during proliferation and differentiation in embryogenesis and adult, if disrupted could possibly lead to cancer. ${ }^{14,15}$ In line with this, SOX9 shows overexpression in many types of cancer and the expression correlated with malignancy and progression of cancer. ${ }^{7,15}$ SOX9 was shown to play a role as oncogene via overexpression in multiple types of cancer such as colorectal, glioma, and pancreatic cancers. ${ }^{7,10,16}$ SOX factors lead to tumourigenesis by regulating B-catenin/TCF activity and the oncogenic Wnt-target genes expression such as Cyclin-D1 and C-Myc. ${ }^{17}$ Bmi1 expression was found to be regulated by SOX 9 binding to Bmi1 promoter in mouse and colorectal neoplasm cells. ${ }^{7}$ There is evidence that SOX9 acts as a direct target of miR105 and miR-145 in glioma. ${ }^{18,19}$ On the other hand, SOX9 (Location: 17qc24.3) was listed among the genes that is up-regulated in atypical and anaplastic meningiomas as compared to benign meningiomas. ${ }^{20}$

Despite being widely studied and many update discoveries revealing SOX9 regulation in the development of CNS tumours, such studies in Asian population specifically Malaysian population are still lacking. Thus, this study objective was to determine SOX9 expression level in several types of brain tumours namely glioma, meningioma and secondary tumours in East Coast Malaysia. This study will enhance our knowledge on SOX9 gene expression among Malay population which can be used as a prognostic marker for these tumours. This also could provide deeper understanding on the role of SOX9 which has not been well-explained because of their distinct activities in different cancers, region of tumours and perhaps varies across ethnicity. However, further functional tests should be performed to confirm SOX9 functions and mechanism in this specific populations.

\section{MATERIALS AND METHODS}

\section{Sample collection}

This pilot study utilized a total of 5 samples which were collected from Department of Pathology, Hospital Universiti Sains Malaysia (HUSM), Kubang Kerian which is a tertiary hospital in the state of Kelantan. HUSM is the neurosurgery referral centre for brain and spinal cord injuries especially from secondary hospitals in Kelantan and Terengganu. The samples consisted of 1 low grade glioma, 1 high grade glioma, 1 high grade meningioma, 1 low grade meningioma and 1 secondary brain tumour. The types of brain tumours were categorized according to a systematic guidelines and this present study implemented the latest 2016 WHO classification system. ${ }^{21}$ All five samples were of Malay descendants. A non-neoplastic brain tissue was included as control.

\section{RNA extraction \& quantification}

Each formalin-fixed pariffin-embedded (FFPE) brain tumour sample was sectioned into 4 slices of $10 \mu \mathrm{l}$ thickness using microtome. The paraffin wax was removed prior to the addition of deparaffinization solution. The extraction was then performed by using FFPE RNA extraction kit, (Macharey Nagel, Germany). All steps were completed according to manufacturer's instruction with slight modification by adding Trizol during tissue lysis. $50 \mu$ RNA was eluted from each sample by using Rnase free water provided with the kit. Only $1 \mu \mathrm{l}$ of RNA was dropped into the well of QuickDrop ${ }^{\text {TM }}$ Micro-Volume Absorbance Spectrophotometer (SpectraMax, USA) to obtain a ratio of $260 / 280$ and $260 / 230$ reading to determine the purity of RNA sample. The RNA quantification was tabulated in Table 1. RNA samples were diluted and standardized to $100 \mathrm{ng} / \mathrm{ul}$ prior to cDNA conversion process.

Table I Concentration and purity of each sample.

\begin{tabular}{lccc}
\hline $\begin{array}{l}\text { Types of brain } \\
\text { tumour }\end{array}$ & $\begin{array}{c}\text { Concentration } \\
\text { (ng/ul) }\end{array}$ & $260 / 280$ & $260 / 230$ \\
\hline $\begin{array}{l}\text { Glioma I } \\
\text { Glioma WHO }\end{array}$ & 527.2 & 2.070 & 1.767 \\
$\begin{array}{l}\text { III } \\
\text { Meningioma }\end{array}$ & 746.4 & 1.952 & 1.855 \\
WHO I & 1856.0 & 2.032 & 1.778 \\
Meningioma & 2248.0 & 1.070 & 1.151 \\
WHO II & 254.4 & 1.963 & 1.855 \\
Secondary & 132.0 & 1.340 & 1.833 \\
\hline Control & & & \\
\hline
\end{tabular}




\section{cDNA conversion}

iScript family of reverse transcription reagents (Biorad, USA) were used to perform CDNA conversion in this study. All RNA samples were normalized to $100 \mathrm{ng} / \mathrm{ul}$. cDNA synthesis reaction was performed on ice. The component reaction volume for cDNA synthesis are $4 \mu \mathrm{l} 5 \mathrm{x}$ iScript advanced reaction mix, $1 \mu \mathrm{l}$ iScript advanced reverse transcriptase, $10 \mu \mathrm{l}$ RNA sample and 5ul nuclease free water. Total reaction volume for each reaction is $20 \mu \mathrm{l}$.

The cDNA synthesis reaction mix was conducted in a thermal cycler (Biorad, USA) using the following protocol; reverse transcription for 30 minutes at 24 ${ }^{0} \mathrm{C}$; reverse transcription inactivation for 5 minutes at $85{ }^{\circ} \mathrm{C}$. At the end of CDNA synthesis, CDNAs were diluted to $100 \mathrm{ul}$ to obtain $20 \mathrm{ng} / \mathrm{ul}$ cDNA and stored under $-20{ }^{\circ} \mathrm{C}$ for short-term storage.

\section{Real-time PCR}

From each cDNA solution, $1 \mu \mathrm{l}$ (20ng CDNA) of the solution was amplified in real-time polymerase chain reaction (RT-PCR) by using StepOnePlus Real-time PCR System (Applied Biosystem, USA). qPCR was performed according to PrimePCR Sybr Green Assays (Biorad, USA) protocols. All reaction mixes were prepared on ice by adding all required components. The component reaction volume for $\mathrm{QPCR}$ experiment are $1 \mu \mathrm{l} 20 \mathrm{x}$ PrimePCR assay (SOX9), $4 \mu \mathrm{l}$ 2x SsoAdvanced universal SYBR Green supermix, 10 $\mu \mathrm{l}$ cDNA sample and $5 \mu \mathrm{l}$ Nuclease-free water. Total reaction volume for each reaction was $20 \mu$ l. Each sample was run in triplicate to set a reliable result on gene expression.

20ul of PCR reaction mix was transferred into each 96-well plate and loaded into PCR instrument. The thermal cycling protocol is according to Table 2. The qPCR results were analysed by using StepOne Software Version 2.3.

Table II Thermal cycling protocol for qPCR experiment

\begin{tabular}{|c|c|c|c|}
\hline Step & Temperature & Time & $\begin{array}{l}\text { No. of } \\
\text { cycles }\end{array}$ \\
\hline Activation & $95^{\circ} \mathrm{C}$ & $2 \min$ & 1 \\
\hline Denaturation & $95^{\circ} \mathrm{C}$ & $5 \mathrm{sec}$ & 40 \\
\hline $\begin{array}{l}\text { Annealing/ } \\
\text { Extension }\end{array}$ & $60^{\circ} \mathrm{C}$ & $30 \mathrm{sec}$ & 40 \\
\hline Melt Curve & $\begin{array}{l}65-95{ }^{\circ} \mathrm{C} \\
\left(0.5{ }^{\circ} \mathrm{C}\right. \\
\text { increments) }\end{array}$ & $\begin{array}{l}5 \mathrm{sec} / \\
\text { step }\end{array}$ & 1 \\
\hline
\end{tabular}

\section{Statistical Analysis}

Data analysis was further interpreted by using Graphpad Prism and Microsoft 2013. One-way ANOVA was performed to evaluate statistical differences between different groups. $P$ values less than 0.05 were considered statistically significant. Since this was a pilot study, the sample size was adequate to perform the analysis with triplicate run for each samples. ${ }^{22}$

\section{RESULTS}

The expression of all brain tumour samples were normalized to non-neoplastic brain tissue $(\mathrm{N})$ and the relative quantification (RQ) of SOX9 expression levels are tabulated in Table 3. The SOX9 levels in pilocytic astrocytoma (G1), anaplastic astrocytoma (G3), benign meningioma (M1), atypical meningioma (M2) and secondary brain tumour (2') were $1.16 \pm$ $0.88(p<0.01), \quad 2.87 \pm 0.32(p>0.01), \quad 3.14 \pm 0.22$ $(p>0.01), 1.66 \pm 1.25(p<0.01)$ and $2.51 \pm 0.29$ $(p<0.01)($ mean $\pm S E M)$ respectively.

SOX9 conferred slightly up-regulation in high grade glioma (anaplastic astrocytoma) in this study. In contrast, SOX9 was up-regulated significantly in low grade glioma (pilocytic astrocytoma). Benign meningioma was seen having slight up-regulation of SOX9, while atypical meningioma showed higher overexpression of the gene when compared to the normal brain tissue. Overall, SOX9 were overexpressed in all brain tumour samples.

\section{DISCUSSION}

SOX9 which is a member of SOXE family has been studied to play a critical role in both embryonic and adulthood CNS and is a key determinant in the neural stem cells (NSCs) multipotency. ${ }^{12,13}$ There were many studies conducted to prove that SOX9 and the other members of SOX E (SOX8 and SOX10) contributed in CNS development..$^{8-11}$ Similarly like other SOX family members, the function of SOX9 is initiatiated when collaborate with other SOX in neurogenesis. The supplementary function of SOX9 with SOX10 may sustain the multipotency of neural crest stem cells of SOX and CNS tumours and commanding differentiating cells to non-neuronal fates. ${ }^{23}$ SOX2 expression in neuroectoderm cells with induction of $50 \times 9$ enhances NSC formation while in the absence of SOX2, SOX9 expression can distinguishes neural crest progenitor. ${ }^{12}$ 
Sox9 acts as mediator for Sonic Hedgehod (SHH) and Notch Pathways to enhance NSC activities. Previous studies have revealed the link between $\mathrm{SHH}$ signaling and SOX9 expression in CNS. However a direct relationship between $\mathrm{SHH}$ and $\mathrm{SOX} 9$ is yet to be determined. There is also a possibility that the induction of SOX9, at least in hippocampus, was either directly or indirectly caused by SOX2 regulated-SHH signalling. In addition, SOX9 expression and function in proliferation, invasion and apoptosis has been observed to be dependent on regional characteristic of different parts of CNS.

Table 3 SOX9 expression level in five cases of brain tumour

\begin{tabular}{lllllllll} 
BT & $\begin{array}{l}\text { Ct } \\
\text { (mean) }\end{array}$ & $\begin{array}{l}\text { Ct } \\
\text { (SD) }\end{array}$ & $\begin{array}{l}\text { dCT } \\
\text { (mean) }\end{array}$ & $\begin{array}{l}\text { dCT } \\
\text { (SE) }\end{array}$ & ddCT & RQ & $\begin{array}{l}\text { Sig. } \\
\text { (p<0.05) }\end{array}$ & SOX9 expression \\
\hline G1 & 35.08 & 0.20 & $1.16^{* * * *}$ & 0.88 & -2.06 & 4.17 & Yes & Up-regulated \\
G3 & 32.65 & 0.49 & 2.87 & 0.32 & -0.35 & 1.28 & No & Up-regulated \\
M1 & 32.75 & 0.18 & 3.14 & 0.22 & -0.09 & 1.06 & No & Up-regulated \\
M2 & 34.39 & 0.56 & $1.66^{* * * *}$ & 1.25 & -1.57 & 2.97 & Yes & Up-regulated \\
$2^{\prime}$ & 33.22 & 0.28 & $2.51^{* *}$ & 0.29 & -0.72 & 1.64 & Yes & Up-regulated \\
N & 31.86 & 0.52 & 3.22 & 0.61 & 0 & 1 & & - \\
\hline
\end{tabular}

BT: Brain tumours, Ct: Threshold cycle, dCt: delta threshold cycle, ddCt: delta delta threshold cycle, $R Q:$ relative quantification.

Gliomas represent the main type of primary brain tumour and are often linked with poor prognosis due to their highly aggressive progression and their frequent resistance to therapy. The glial development has been found to be regulated by SOX $\mathrm{E}$ group of gene including SOX9 when tested with mouse mutants. ${ }^{13}$ Before gliogenesis occurs, SOX9 is initially expressed in the entire neuroepithelium of the spinal cord. ${ }^{13,24}$

In 2007, a study was done in Germany on SOX9 expression levels in glioma showed that SOX9 gene was up-regulated in most of low grade astrocytoma and expressed variably in higher grade astrocytoma (anaplastic astrocytoma and glioblastoma). ${ }^{11}$ A study done in China strengthened the evidence when the averaged level of SOX9 mRNA expression in glioma tissues was observed in both low and high grade glioma (not including oligodendroglioma) was significantly higher than that in normal brain tissues. ${ }^{10} \mathrm{~A}$ recent review comparing the overall survival of patients of solid tumours with the overexpression of SOX9 revealed an obvious tumour growth promotion by SOX9. ${ }^{15}$ These studies are consistent with our finding whereby SOX 9 were upregulated in both grades of glioma. However, SOX9 was found in all grades of glioma with slightly lower expression in pilocytic astrocytomas during protein analysis. ${ }^{25}$

SOX9 is believed to play an important roles in glioma progression and development due to its propensity to elevate the expression according to WHO grading progression. ${ }^{10,15}$ In the light of the recent micro-RNAs involvement in cancer research, several oncogenes miRNAs have been identified to be overexpressed in glioma including miR-21, miR-328, miR-145 and miR-105, while several of the miRNAs act as tumour suppressor and being downregulated for instance, miR-137 and miR-6500-3p. There was evidence that SOX 9 acts as a direct target of miR-105 and miR-145 in glioma. ${ }^{18,19}$ miRNA-105 expression was decreased and inversely correlated with SOX9 mRNA expression in glioma. This down-regulation of SOX9 has been found to inhibit proliferation and invasion of glioma cells while promoting apoptosis, a programmed cell death. ${ }^{19}$ When binding to miR-145, SOX9 inhibition showed tumour suppression, antimigratory and anti-invasive potential in glioma and glioma stem cells. ${ }^{18}$

The result might suggest that downregulation of SOX9 effected glioma growth pattern in the same way as those miR-145-expressing cells. These evidence strongly supported our finding of Sox9 expression in glioma. SOX9 expression in low grade glioma was up-regulated but in contrary, being downregulated in high grade glioma. We hypothesized that the mechanisms of SOX9 regulation would varied depending to glioma grading. Thus, the direct relationship and which miRNAs involved to inhibit or induce SOX9 expression is yet to be determined. 
SOX factors may lead to tumourigenesis by regulating $B$-catenin/TCF activity and the oncogenic Wnt-target genes expression such as Cyclin-D1 and $c$ -Myc. ${ }^{17}$ SOX9 factors and WNT signalling have interacted by modulating beta-catenin/TCF activities in various mechanism including, SOX9beta catenin interaction, DNA binding, transcriptional cofactors recruitment, protein degradation and nuclear translocation. ${ }^{26-32}$ There is also evidence that SOX9 involved in regulating BMI1 expression in animal embryo fibroblast and colorectal cancer cells by binding to BMI1 promoter in which the overexpression of BMI1 reduced the expression of Ink4a/Arf in human colorectal cancers. ${ }^{7}$ However, further investigation should be done to analyse the pathway in brain cancers.

Globally, meningioma are the second-most frequent CNS tumours in adults. Recent study done in East Coast Malaysia revealed that meningioma was accounted for more that $30 \%$ of CNS tumour occurence. Thus the data projected meningiomas as the most frequent CNS tumour in that region. ${ }^{4}$ Meningiomas are common intracranial or spinal tumours and are derived from the arachnoid cells covering the brain and spinal cord. Clinically and histologically, meningiomas are subdivided into benign (WHO grade I), atypical (WHO grade II) and malignant (WHO grade III). Molecular genetic alterations have been linked to meningioma tumourigenesis particularly affecting cell cycle, DNA damage repair, apoptosis and angiogenesis. ${ }^{33}$ There are countless descriptions of chromosomal, signaling pathways and growth factors aberrations regarding meningiomas. Overall, the knowledge of meningioma molecular genetics is developing. However, they are still largely unknown and should be further elucidated. In low grade meningioma, several gene mutations and aberrations have been established including Neurofibromatosis 2 (NF2) mutations on chromosome 22 with loss of merlin expression, loss of protein 4.1B (DAL-1) expression, epidermal growth factor receptor (EGFR) overexpression, and platelet-derived growth factor receptor beta (PDGFRB) overexpression. ${ }^{34-37}$

In high-grade meningioma, more than half percentage have shown point mutations in chromosomes. ${ }^{38}$ Other than Chromosome 22q, Chromosomes $1 p$ and $14 q$ mutations have been stated as the second most frequent genetics aberrations in meningioma. ${ }^{39}$ Chromosome 1 mutations leads to aggresiveness of meningioma tumours in higher grade glioma in comparison to lower grade. In addition, the mutations of Chromosomes 10 and 14 in meningioma are usually deletions which associated with gene expression profiles that involves largely up-regulation of genes in Wnt pathways and insulin like growth factors. ${ }^{40-42}$ Our findings showed that SOX9 expression was upregulated in both benign and atypical meningioma. However, atypical meningioma displayed higher expression of SOX9 with 2.97 fold differences in compared to normal brain control than benign meningioma which showed lower expression of 1.06 fold difference in compared to normal brain control. This is comparable with previous study whereby SOX9 (Location: 17q24.3) were listed among genes that are up-regulated in atypical and anaplastic meningiomas as compared to benign meningiomas. ${ }^{20}$ To the best of our knowledge, no further investigation has been done to clarify the mechanism between SOX9 and meningioma.

Secondary brain tumours, a common source of morbidity and mortality for cancer patient are also known as brain metastases are cancer cells developed primarily elsewhere which spread to the brain. ${ }^{43,44}$ The characteristic of these cancer cells resemble the cells where they are originated. For examples, brain metastases from lung cancer cells could be recognized by their resemblance with lungs cell's morphology. The occurence of brain metastases is driven by several steps commenced by molecular alterations of genetics and epigenetics changes. ${ }^{45,46}$ Several genes were observed to involve in brain metastases. Inhibition of COX2, HBEGF and ST6GALNAC5 in breast cancer cells repress penetration of an artificial Blood Brain Barrier (BBB), and promotes brain metastases. ${ }^{45}$ LEF1 and HOXB9 are thought to be involved in lung metastasize to brain. The knockdown of LEF1 and HOXB9 inhibited brain metastasis, and reduced colony formation and invasion. ${ }^{47}$ STAT3 knockdown repressed brain metastases by disrupting angiogenesis in vivo and cell invasion in vitro. ${ }^{48}$ VEGFA, an angiogenic growth factor is found to be involved in brain metastases formation from primary site, breasts, melanoma, lungs and colon. ${ }^{46,49}$ The roles of SOX9 in brain metastases formation is still undetermined. However, significant up-regulation of SOX9 in secondary brain tumour in our study is worth to be noted and the involvement of SOX9 in brain metastases molecular biology should be further studied. 
As conclusion, SOX9 has played significant roles in brain tumourigenesis. Numerous studies have proved its diverse functions across human organs and abilities to enhance cell proliferations, invasion and apoptosis. The SOX9 expression levels in selected brain tumours in Malaysia population were determined. For future directions, functional studies are warranted to examine the function and mechanism of SOX9 in Malaysia population.

\section{ACKNOWLEDGEMENTS}

This study was supported by the Fundamental Research Grant Scheme (FRGS) (No grant: FRGS/2/2014/SKK01/UNISZA/02/2) and approved by National Medical Research Register. The study protocol obeys the ethical guidelines of the Research Review Board and Human Research Ethics Committee of Universiti Sains Malaysia, Kelantan, Malaysia (JEPeM Code: USM/JEPeM/16030095).

\section{REFERENCES}

1. Zainal Ariffin O, Nor Saleha T. National Cancer Registry Report 2007.; 2011.

2. Goh CH, Lu YY, Lau BL, et al. Brain and Spinal Tumour. Med J Malaysia. 2014;69(6):261-267.

3. Bray F, Ferlay J, Soerjomataram I, Siegel RL, Torre LA, Jemal A. Global Cancer Statistics 2018: GLOBOCAN Estimates of Incidence and Mortality Worldwide for 36 Cancers in 185 Countries. CA Cancer J Clin. 2018;11:394-424.

4. Md Dzali NB, Zahary MN, Abu Bakar NH, Jaafar $\mathrm{H}$, Wan Taib WR. Distribution Pattern Of Brain Tumour In A Tertiary Hospital In East Coast Malaysia. Malaysian J Public Heal Med. 2017; (2):41-48.

5. Tevlin R, Larkin JO, Hyland JM, O'Connell PR, Winter DC. Brain metastasis from colorectal carcinoma: a single cancer centre experience. Ir J Med Sci. 2015;184(3):673-675.

6. Nayak L, Lee EQ, Wen PY. Epidemiology of brain metastases. Curr Oncol Rep. 2012;14 (1):48-54.

7. Matheu A, Collado M, Wise C. Oncogenicity of the Developmental Transcription Factor Sox 9 Oncogenicity of the Developmental Transcription Factor. Cancer Res. 2012:13011315.

8. Ferletta M. The Role of Sox Transcription Factors in Brain Tumourigenesis. In: Molecular Targets of CNS Tumours. Ed. Garami, Miklos. Rijeka: In Tech, 2011:99-124.
9. de la Rocha AMA, Sampron N, Alonso MM, Matheu A. Role of SOX family of transcription factors in central nervous system tumours. Am J Cancer Res. 2014;4(4):312-324.

10. Wang L, He S, Yuan J, et al. Oncogenic role of SOX9 expression in human malignant glioma. Med Oncol. 2012:3484-3490.

11. Schlierf B, Friedrich RP, Roerig P, Felsberg J, Reifenberger $G$, Wegner M. Expression of SoxE and SoxD genes in human gliomas. Neuropathol Appl Neurobiol. 2007;33(6):621-630.

12. Scott CE, Wynn SL, Sesay A, et al. SOX9 induces and maintains neural stem cells. Nat Publ Gr. 2010;13(10):1181-1189.

13. Stolt CC, Lommes $P$, Sock E, Chaboissier $M$, Schedl A, Wegner M. The Sox 9 transcription factor determines glial fate choice in the developing spinal cord. Genes Dev. 2003:16771689.

14. Jo A, Denduluri S, Zhang B, et al. ScienceDirect The versatile functions of Sox 9 in development, stem cells, and human diseases. Genes Dis. 2014;1(2):149-161.

15. Ruan H, Hu S, Zhang $\mathrm{H}$, et al. Upregulated SOX9 expression indicates worse prognosis in solid tumours: a systematic review and metaanalysis. Oncotarget. 2017;8(68):113163113173.

16. Kopp JL, Figura G Von, Mayes E, et al. Identification of Sox9-dependent acinar-toductal reprogramming as the principla mechanism for initiation of pancreatic ductal adenocarcinoma. Cancer Cell. 2012;22(6):737750.

17. Kormish JD, Zorn AM. Interactions Between SOX Factors and Wnt / beta- Catenin Signaling in Development and Disease. Dev Dyn. 2010; (August 2009):56-68.

18. Rani SB, Rathod SS, Karthik S, et al. MiR-145 functions as a tumour-suppressive RNA by targeting Sox 9 and adducin 3 in human glioma cells. Neuro Oncol. 2013;15(November 2017):1302-1316.

19. Liu X, Wang H, Zhu Z, Ye Y, Mao H, Zhang S. MicroRNA-105 targets SOX9 and inhibits human glioma progression. FEBS Lett. 2016.

20. Wrobel G, Roerig P, Kokocinski F, et al. Microarray-based gene expression profiling of benign, atypical and anaplastic meningiomas identifies novel genes associated with meningioma progression. Int $\mathrm{J}$ cancer. 2005;114:249-256. 
21. Louis DN, Perry A, Reifenberger G, et al. The 2016 World Health Organization Classification of Tumours of the Central Nervous System: a summary. Acta Neuropathol. 2016;131(6):803820.

22. Iterson M Van, Hoen PAC, Pedotti P, et al. Relative power and sample size analysis on gene expression profiling data. BMC Genomics. 2009;10(439):1-10.

23. Chew L-J, Gallo V. The Yin and Yang of Sox proteins: Activation and repression in development and disease. J Neurosci Res. 2009;87(15):3277-3287.

24. Stolt CC, Wegner M. SoxE function in vertebrate nervous system development. Int J Biochem Cell Biol. 2010;42:437-440. doi:10.1016/j.biocel.2009.07.014.

25. Kordes U, Hagel C. Expression of SOX9 and SOX10 in central neuroepithelial tumour. $J$ Neurooncol. 2006;80:151-155.

26. Akiyama $\mathrm{H}$, Lyons JP, Mori-akiyama $\mathrm{Y}$, et al. Interactions between Sox 9 and beta-catenin control chondrocyte differentiation. Genes Dev. 2004:1072-1087.

27. Bastide P, Darido C, Pannequin J, et al. Sox9 regulates cell proliferation and is required for Paneth cell differentiation in the intestinal epithelium. J Cell Biol 2007;178(4):635-648.

28. Dichtel-Danjoy M-L, Caldeira J, Casares F. SoxF is part of a novel negative-feedback loop in the wingless pathway that controls proliferation in the Drosophila wing disc. Development. 2009;136:761-769.

29. Tsuda M, Takahashi S, Takahashi Y, Asahara H. Transcriptional co-activators CREB-binding protein and $\mathrm{p} 300$ regulate chondrocytespecific gene expression via association with Sox9. J Biol Chem. 2003;278(29):27224-27229.

30. Furumatsu T, Tsuda M, Yoshida K, et al. Sox 9 and p300 cooperatively regulate chromatinmediated transcription. J Biol Chem. 2005;280 (42):35203-35208.

31. Topol L, Chen W, Song H, Day TF, Yang Y. Sox9 Inhibits Wnt Signaling by Promoting BetaCatenin Phosphorylation in the Nucleus. J Biol Chem. 2009;284(5):3323-3333.

32. Kiefer JC. Back to basics: Sox genes. Dev Dyn. 2007;236(8):2356-2361.

33. Torres-Martín M, Martinez-Glez V, PeñaGranero C, et al. Gene expression analysis of aberrant signaling pathways in meningiomas. Oncol Lett. 2013;6(1):275-279.
34. Perry A, Gutmann DH, Reifenberger G. Molecular pathogenesis of meningiomas. $J$ Neurooncol. 2004;70(2):183-202.

35. Saraf S, McCarthy BJ, Villano JL. Update on Glioma. Oncologist. 2010;15(suppl 1):11-12.

36. Dickinson PJ, Surace El, Cambell M, et al. Expression of the Tumour Suppressor Genes NF2, 4.1B, and TSLC1 in Canine Meningiomas. Vet Pathol. 2009;46(5):884-892.

37. Pham MH, Zada G, Mosich GM, et al. Molecular genetics of meningiomas: a systematic review of the current literature and potential basis for future treatment paradigms. Neurosurg Focus. 2011;30(5):1-9.

38. Wernicke AG, Dicker AP, Whiton M, et al. Assessment of Epidermal Growth Factor Receptor (EGFR) expression in human meningioma. Radiat Oncol. 2010;5(1):46.

39. Cai DX, Banerjee R, Scheithauer BW, Lohse CM, Kleinschmidt-Demasters BK, Perry A. Chromosome $1 p$ and $14 q$ FISH analysis in clinicopathologic subsets of meningioma: diagnostic and prognostic implications. . Jun; J Neuropathol Exp Neurol. 2001;60(6):628-636.

40. Wellenreuther R, Kraus JA, Lenartz D, et al. Analysis of the neurofibromatosis 2 gene reveals molecular variants of meningioma. $\mathrm{Am}$ J Pathol. 1995;146(4):827-832.

41. Heinrich B, Hartmann C, Stemmer-Rachamimov AO, Louis DN, MacCollin M. Multiple meningiomas: Investigating the molecular basis of sporadic and familial forms. Int $J$ Cancer. 2003;103(4):483-488.

42. Tabernero $M$, Jara-Acevedo $M$, Nieto $A B$, et al. Association between mutation of the NF2gene and monosomy 22 in menopausal women with sporadic meningiomas. BMC Med Genet. 2013;14(1):114.

43. Association ABT. Metastatic Brain Tumours. American Brain Tumour Association (ABTA). www.abta.org/secure/metastatic-braintumour.pdf. Published 2017. Accessed November 25, 2017.

44. Hardesty DA, Nakaji P. The Current and Future Treatment of Brain Metastases. Front Surg. 2016;3(May):1-7.

45. Macaluso M, Paggi MG, Giordano A. Genetic and epigenetic alterations as hallmarks of the intricate road to cancer. Oncogene. 2003;22:6472.

46. Bielenberg DR, Zetter BR. The Contribution of Angiogenesis to the Process of Metastasis. 
Cancer J (United States). 2015;21(4):267-273.

47. Nguyen DX, Chiang AC, Zhang XH-F, et al.

WNT/TCF Signaling through LEF1 and HOXB9

Mediates Lung Adenocarcinoma Metastasis.

Cell. 2009;138(1):51-62.

48. Xie TX, Huang FJ, Aldape KD, et al. Activation of Stat3 in human melanoma promotes brain metastasis. Cancer Res. 2006;66(6):3188-3196.

49. Kim LS, Huang S, Lu W, Lev DC, Price JE.

Vascular endothelial growth factor expression promotes the growth of breast cancer brain metastases in nude mice. Clin Exp Metastasis. 2004;21(2):107-118. 